\title{
Anti-Candida Activity of Sodium Sulfite
}

\author{
Ayako Ogasawara, * Yuki Iino, Keio Sato, Yuta Nakajima, Satoko Bessho, Toshihiko Watanabe, \\ Takeshi Mikami, and Tatsuji Matsumoto \\ Department of Microbiology, Tohoku Pharmaceutical University; 4-4-1 Komatsushima, Aoba-ku, Sendai 981-8558, \\ Japan. Received January 10, 2008; accepted March 20, 2008; published online March 31, 2008
}

The growth of Candida albicans in RPMI1640 medium was inhibited by sodium sulfite between pH 3-6. Under the condition of pH 7, growth of $C$. albicans was not inhibited by sodium sulfite. Under an acidic pH condition, sodium sulfite had a candidacidal effect and the activity was expressed within $150 \mathrm{~min}$. The concentration of ATP in $C$. albicans was decreased by sodium sulfite. Ethanol production by $C$. albicans was inhibited by sodium sulfite at $\mathbf{p H} 5$. These results indicated that the candidacidal effect of sodium sulfite under acidic conditions was caused by interruption of alcohol fermentation and aerobic respiration.

Key words Candida albicans; sodium sulfite; $\mathrm{pH}$

The opportunistic fungus Candida albicans is the most important fungus in the case of oral and deep-seated infections. $C$. albicans is able to grow in yeast and hyphal forms depending on environmental conditions. ${ }^{1,2)}$ The external $\mathrm{pH}$ and temperature induce morphological transition in C. albicans. ${ }^{3)} C$. albicans can grow under conditions ranging from pH 2 to 10. ${ }^{4}$ The hyphal growth is observed above $\mathrm{pH} 6$ and yeast growth is observed below $\mathrm{pH} 5{ }^{5}{ }^{5}$ Under aerobic conditions, glucose is metabolized to acetyl CoA via the glycolysis pathway. At this time, the glycolysis pathway generates ATP molecules in the cytoplasm. When acetyl CoA enters the tricarboxylic acid (TCA) cycle in the mitochondrion, NADH is generated. ${ }^{6}$ Then, reoxidation of NADH through the mitochondrial respiratory chain induces a volume of ATP molecules. While under anaerobic condition, the TCA cycle and mitochondrial respiratory chain are terminated, the regeneration of $\mathrm{NAD}^{+}$is caused by the alcohol fermentation pathway. In this pathway, acetaldehyde plays a role as the exogenous electron acceptor to produce ATP. ${ }^{7)}$

Sodium sulfite is used as a leading food preservative. ${ }^{8)}$ As sodium sulfite binds to oxygen and induces an anaerobic condition $\left.\left(2 \mathrm{Na}_{2} \mathrm{SO}_{3}+\mathrm{O}_{2}=2 \mathrm{Na}_{2} \mathrm{SO}_{4}\right),{ }^{9}\right)$ the growth of aerobic microorganisms is effectively inhibited. Sodium sulfite showed a negative effect on mutagenicity studies and was not irritating or sensitizing on clinical tests. ${ }^{10)}$ There are a few studies describing the effects of sodium sulfite on human neutrophils and macrophages, in which activation of superoxide production and gene expression by sulfite are demonstrated. $^{11-13)}$ However, there is no report about the effect of sodium sulfite on $C$. albicans, a facultative anaerobic fungus.

In this study, we demonstrated that sodium sulfite showed an anti-Candida activity under acidic conditions, and described its activity.

\section{MATERIALS AND METHODS}

Reagent Sodium sulfite (Nacalai Tesque) was used in this study.

Fungus Candida albicans BWP yeast cells was maintained at $27^{\circ} \mathrm{C}$ in Sabouraud's liquid medium ( $2 \%$ glucose, $1 \%$ peptone and $0.5 \%$ yeast extract) with shaking for $24 \mathrm{~h}$. After the incubation, the yeast cells were washed with sterilized water, then suspended in RPMI1640 medium (Nissui) for various experiments.
Effect of Sodium Sulfite on the Growth of $\boldsymbol{C}$. albicans To monitor the effect of $\mathrm{pH}$ on the anti-Candida activity of sodium sulfite, RPMI1640 medium mixed with sodium sul-

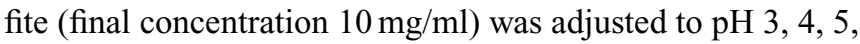
6 and 7 by adding $1 \mathrm{~N} \mathrm{HCl}$ solution, respectively. C. albicans BWP (final concentration $1 \times 10^{5}$ cells $/ \mathrm{ml}$ ) was suspended in $\mathrm{pH}$-adjusted RPMI1640 medium and incubated at $37^{\circ} \mathrm{C}$ in $5 \% \mathrm{CO}_{2}$ for $24 \mathrm{~h}$. After incubation, the total number of cells was measured at $\mathrm{OD}_{620}$ using Immuno Mini NJ-2300 (Inter Med). To examine whether the effect of sodium sulfite is candidacidal or candidastatic, $C$. albicans cells treated with sodium sulfite were harvested and washed twice with sterilized water, then the cells were suspended in fresh RPMI 1640 medium (pH 7). Twenty-four hours after incubation at $37^{\circ} \mathrm{C}$ in $5 \% \mathrm{CO}_{2}$, the total number of cells was measured by the absorbance at $\mathrm{OD}_{620}$.

Measurement of ATP RPMI1640 medium mixed with sodium sulfite (final concentration $10 \mathrm{mg} / \mathrm{ml}$ ) was adjusted to pH 5 by adding $1 \mathrm{~N} \mathrm{HCl}$. C. albicans BWP was added to this medium (final concentration $1 \times 10^{5}$ cells $/ \mathrm{ml}$ ), and incubated at $37^{\circ} \mathrm{C}$ in $5 \% \mathrm{CO}_{2}$ for $30,60,90,120$ and $150 \mathrm{~min}$, respectively. After incubation, C. albicans were washed with sterilized water, and the ATP concentration in cells was measured using CheckLite 250 plus kit (Kikkoman). Using this kit, ATP could be detected as fluorescence intensity: (ATP $+\mathrm{Lu}-$ ciferin $+\mathrm{O}_{2}+$ Luciferase $+\mathrm{Mg}^{2+} \rightarrow$ Oxyluciferin $+\mathrm{AMP}+\mathrm{PPi}$ $+\mathrm{CO}_{2}+$ fluorescence). The relative fluorescence unit (RLU) was measured by Luminometer, MiniLumat LB9506 (Berthold, Germany). The number of cells was also counted by hemocytometer, and the amount of ATP per cell was calculated.

Ethanol Production of $C$. albicans C. albicans $\left(1 \times 10^{5}\right.$ cells $/ \mathrm{ml}$ ) was incubated in RPMI1640 medium mixed with/without sodium sulfite ( $\mathrm{pH} 5$ or 7 ) at $37^{\circ} \mathrm{C}$ in $5 \% \mathrm{CO}_{2}$. The culture supernatants were harvested $2 \mathrm{~h}$ after the incubation, and then the supernatants were heated $\left(95^{\circ} \mathrm{C}, 5 \mathrm{~min}\right)$. The ethanol concentration in each supernatant was detected by F-Kit (R-Biopharm AG). Quantity of C. albicans under this condition was measured by the absorbance at $\mathrm{OD}_{620}$, and calculated as the number of cells. The amount of ethanol per $1 \times 10^{5}$ cells was shown in a result.

Statistical Analysis Values are shown as means \pm standard error, and statistical analyses of these data were performed using the Student's $t$-test. 


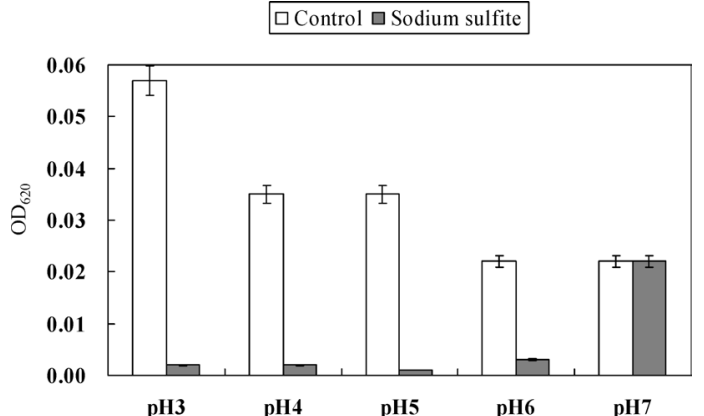

Fig. 1. Effect of Sodium Sulfite on the Growth of C. albicans under Various $\mathrm{pH}$ Conditions

C. albicans BWP $\left(1 \times 10^{5}\right.$ cells $\left./ \mathrm{ml}\right)$ was incubated with sodium sulfite $(10 \mathrm{mg} / \mathrm{ml})$ in RPMI1640 medium (pH 3-7) at $37^{\circ} \mathrm{C}$ in $5 \% \mathrm{CO}_{2}$ for $24 \mathrm{~h}$. After incubation, the total number of cells was measured by absorbance at $\mathrm{OD}_{620}$.

\section{RESULTS}

Effect of Sodium Sulfite on the Growth of $C$. albicans under Various pH Conditions To study the effect of sodium sulfite on the growth of $C$. albicans under several $\mathrm{pH}$ conditions, $C$. albicans BWP cells were incubated with sodium sulfite in RPMI1640 medium ( $\mathrm{pH} 3-7$ ) for $24 \mathrm{~h}$. As a result, the growth of $C$. albicans was inhibited by the addition of sodium sulfite between the conditions of $\mathrm{pH} 3-6$ (Fig. 1). In the condition of $\mathrm{pH} 7$, the growth of $C$. albicans was not inhibited by sodium sulfite. When $C$. albicans was cultured without sodium sulfite, $C$. albicans could grow under all $\mathrm{pH}$ conditions. To examine whether the anti-Candida activity of sodium sulfite under acidic $\mathrm{pH}$ conditions was candidacidal or candidastatic, $C$. albicans treated with sodium sulfite between $\mathrm{pH} 3-7$ for $24 \mathrm{~h}$ was re-cultured in fresh RPMI1640 medium and growth activities were monitored. In the control group, $C$. albicans could grow under all $\mathrm{pH}$ conditions. $C$. albicans treated with sodium sulfite at $\mathrm{pH}$ 7 resumed growth, however, $C$. albicans treated with sodium sulfite below $\mathrm{pH} 6$ could not grow in fresh RPMI1640 medium (data not shown). These findings indicate that sodium sulfite exhibited candidacidal effect under acidic $\mathrm{pH}$ condition.

Effect of Sodium Sulfite on ATP Concentration in $C$. albicans Because sodium sulfite completely controlled the proliferation of C. albicans under acidic conditions (Fig. 1), the following experiments were performed under $\mathrm{pH} 5$. When the cells were treated with sodium sulfite for 30,60 , 90,120 and $150 \mathrm{~min}$, the proliferation of $C$. albicans was completely inhibited at $150 \mathrm{~min}$ (Fig. 2). Thus, the change in ATP production of $C$. albicans was monitored between 0 to $150 \mathrm{~min}$ to analyze the mechanism of the candidacidal effect of sodium sulfite (Fig. 3). ATP production by $C$. albicans was increased in the control group. In contrast, the concentration of ATP in cells treated with sodium sulfite was decreased.

Effect of Sodium Sulfite on Ethanol Production in $\boldsymbol{C}$. albicans Under anaerobic condition, ATP is produced by alcohol fermentation. ${ }^{7}$ To confirm whether sodium sulfite inhibited fermentation at $\mathrm{pH} 5$, the function of fermentation was measured. In this assay, ethanol production was used as an index of fermentation. As a result, ethanol production was inhibited by addition of sodium sulfite at $\mathrm{pH} 5$ compared

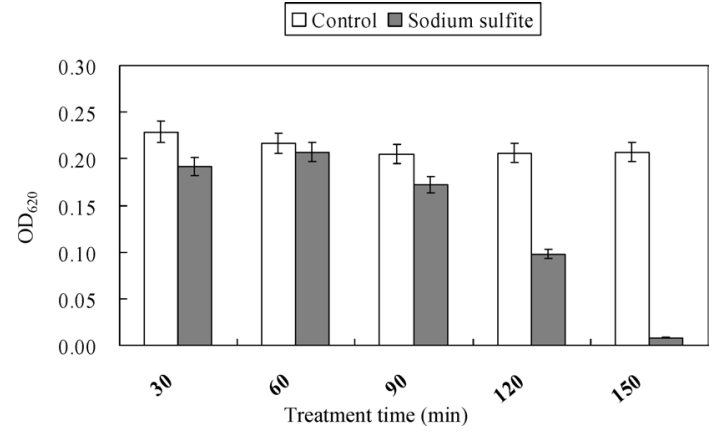

Fig. 2. Appropriate Duration of Treatment with Sodium Sulfite Required to Induce Candidacidal Activity

C. albicans BWP $\left(1 \times 10^{6}\right.$ cells $\left./ \mathrm{ml}\right)$ was treated with sodium sulfite at $\mathrm{pH} 5$ for 30 $60,90,120$ and $150 \mathrm{~min}$, respectively. The cells were harvested and washed twice with sterilized water, then the cells suspended in fresh RPMI1640 medium (pH 7) for incubation at $37{ }^{\circ} \mathrm{C}$ in $5 \% \mathrm{CO}_{2}$. Twenty-four hours after the incubation, the total number of cells was measured as $\mathrm{OD}_{620} \mathrm{~nm}$.

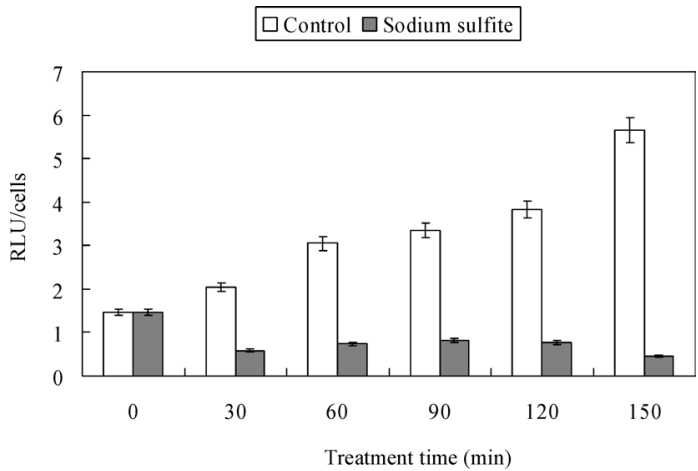

Fig. 3. Amount of ATP in C. albicans Treated with Sodium Sulfite C. albicans BWP $\left(1 \times 10^{5}\right.$ cells $\left./ \mathrm{ml}\right)$ was incubated with sodium sulfite $(10 \mathrm{mg} / \mathrm{ml})$ in RPMI1640 medium (pH 5) at $37^{\circ} \mathrm{C}$ in $5 \% \mathrm{CO}_{2}$ for $30,60,90,120$ and 150 min, respectively. After the incubation, C. albicans was washed by sterilized water, and the amount of ATP in the cells was measured using CheckLite 250 plus kit (Kikkoman).

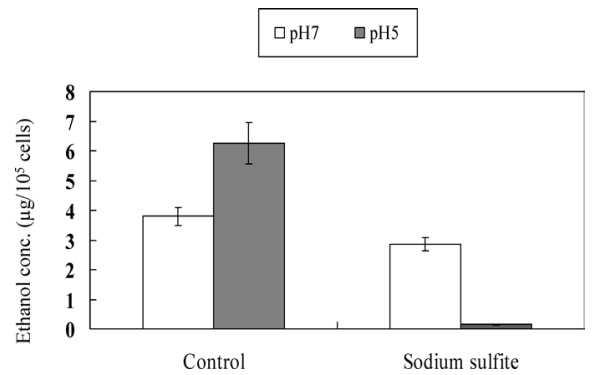

Fig. 4. Effect of Sodium Sulfite on Ethanol Production in C. albicans

C. albicans $\left(1 \times 10^{5}\right.$ cells $\left./ \mathrm{ml}\right)$ was incubated in RPMI1640 medium with/without sodium sulfite ( $\mathrm{pH} 5$ or 7 ) at $37^{\circ} \mathrm{C}$ in $5 \% \mathrm{CO}_{2}$ for $2 \mathrm{~h}$. Ethanol concentrations in supernatants were measured as described in Materials and Methods.

with that in the control (Fig. 4). At pH 7, sodium sulfite did not affect ethanol production.

\section{DISCUSSION}

Sodium sulfite is used as preservative, and inhibits the growth of aerobic bacteria. However, the anti-Candida activity has not previously been clarified. In this study, we demonstrated that sodium sulfite showed anti-Candida activity in acidic condition, and analyzed the mechanism of its activity.

When C. albicans BWP was incubated in RPMI1640 
medium without sodium sulfite, $C$. albicans could grow under conditions ranging from $\mathrm{pH} 3$ to 7 (Fig. 1). However, sodium sulfite inhibited the growth of $C$. albicans under conditions between $\mathrm{pH} 3$ to 6 . At $\mathrm{pH} 7$, there was no growth inhibition following the addition of sodium sulfite. These findings indicated that sodium sulfite expressed anti-Candida activity under acidic condition. The activity was cytotoxic and expressed within 150 min (Fig. 2), suggesting that metabolic interruption by sodium sulfite occurred within $150 \mathrm{~min}$. As ATP is an energy source for the growth of $C$. albicans, we measured the amount of ATP to examine whether sodium sulfite inhibited the ATP production system. Sodium sulfite is an oxygen absorbent and the amount of ATP of $C$. albicans was decreased within $30 \mathrm{~min}$ after the addition of sodium sulfite (Fig. 3), indicating that aerobic ATP production was effectively inhibited by sodium sulfite. ATP is generally generated in both the respiratory chain and the glycolysis pathway under aerobic conditions. However, ATP is also produced by alcohol fermentation when cells are under anaerobic condition. ${ }^{7}$ C. albicans is a facultative fungus in which ATP production is not terminated under anaerobic conditions. Thus, we suggested that sodium sulfite could inhibit not only aerobic respiration but also alcohol fermentation. As shown in Fig. 4, alcohol fermentation at pH 5 was strongly inhibited by sodium sulfite. These findings indicated that the ATP production system, aerobic respiration and alcohol fermentation was interrupted by the treatment of sodium sulfite at $\mathrm{pH}$ 5. The interruption of ATP production might be a cause of growth inhibition of $C$. albicans.

The cause of differences in anti-Candida activity following the addition of sodium sulfite under acidic and neutral condi- tions was not clarified in this study. However, as sodium sulfite generated $\mathrm{SO}_{2}$ gas under acidic conditions, ${ }^{14)} \mathrm{SO}_{2}$ gas might increased oxidative stress in the cells. Although sodium sulfite is widely used as a preservative, the effect may be further developed by reconsideration of treatment methods.

\section{REFERENCES}

1) Odds F. C., Crit. Rev. Microbiol., 12, 45-93 (1985).

2) Nantel A., Dignard D., Bachewich C., Harcus D., Marcil A., Bouin A. P., Sensen C. W., Hogues H., van het Hoog M., Gordon P., Rigby T., Benoit F., Tessier D. C., Thomas D. Y., Whiteway M., Mol. Biol. Cell, 13, 3452-3465 (2002).

3) Buffo J., Herman M. A., Soll D. R., Mycopathologia, 85, 21-30 (1984).

4) Davis D., Curr. Genet., 44, 1-7 (2003).

5) Konno N., Ishii M., Nagai A., Watanabe T., Ogasawara A., Mikami T., Matsumoto T., Biol. Pharm. Bull., 29, 923-926 (2006).

6) Drewke C., Thielen J., Ciriacy M., J. Bacteriol., 172, 3909-3917 (1990).

7) Liu L., Li Y., Shi Z., Du G., Chen J., J. Biotechnol., 126, 173-185 (2006).

8) Schlatter J., Würgler F. E., Kränzlin R., Maier P., Holliger E., Graf U., Food Chem. Toxicol., 30, 843-851 (1992).

9) Allison A. C., Cecil R., Biochem. J., 69, 27-34 (1958).

10) Nair B., Elmore A. R., Int. J. Toxicol., 22, 63-88 (2003).

11) Beck-Speier I., Liese J. G., Belohradsky B. H., Godleski J. J., Free Radic. Biol. Med., 14, 661-668 (1993).

12) Beck-Speier I., Dayal N., Maier K. L., J. Biolumin. Chemilumin., 13, 91-99 (1998).

13) Labbé P., Pelletier M., Omara F. O., Girard D., Hum. Exp. Toxicol., 17, 600-605 (1998).

14) Fine J. M., Gordon T., Sheppard D., Am. Rev. Respir. Dis., 136, 1122 1126 (1987). 